\title{
Correction to: Influence of physico-chemical properties of soil clay fractions on the retention of dissolved organic carbon
}

\author{
Mandeep Singh - Binoy Sarkar (D) - Sabir Hussain - Yong Sik Ok • \\ Nanthi S. Bolan · Gordon Jock Churchman
}

Published online: 4 January 2018

(C) Springer Science+Business Media B.V., part of Springer Nature 2017

\section{Correction to: Environ Geochem Health (2017) 39:1335-1350 \\ https://doi.org/10.1007/s10653-017- 9939-0}

Unfortunately, in the original publication of the article, Prof. Yong Sik Ok's affiliation was incorrectly published. The author's affiliation is as follows.
1. Kangwon National University, Chuncheon 24341, Republic of Korea

2. O-Jeong Eco-Resilience Institute (OJERI), Division of Environmental Science and Ecological Engineering, Korea University, Seoul, Republic of Korea
The original article can be found online at https://doi.org/10.1007/s10653-017-9939-0.

M. Singh · B. Sarkar $(\bowtie)$

Future Industries Institute (FII), University of South

Australia, Mawson Lakes, SA 5095, Australia

e-mail: binoy.sarkar@unisa.edu.au

S. Hussain

Natural and Built Environments Research Centre, School of Natural and Built Environments, University of South Australia, Mawson Lakes, SA 5095, Australia

Y. S. Ok

Department of Biological Environment, Korea Biochar Research Centre, Kangwon National University,

Chuncheon 200701, Republic of Korea

Y. S. Ok

O-Jeong Eco-Resilience Institute (OJERI), Division of Environmental Science and Ecological Engineering, Korea University, Seoul, Republic of Korea

e-mail: yongsikok@korea.ac.kr
N. S. Bolan

Global Centre for Environmental Remediation, University of Newcastle, Callaghan, NSW 2308, Australia

N. S. Bolan

Cooperative Research Centre for Contamination Assessment and Remediation of the Environment, ACT Building, University of Newcastle, Callaghan, NSW 2308, Australia

G. J. Churchman ( $₫)$

School of Agriculture, Food and Wine, University of Adelaide, Urrbrae, SA 5064, Australia e-mail: jock.churchman@adelaide.edu.au 